\title{
The Paleontology of Growth and Development
}

\section{Patterns of Growth and Development in the Genus Homo \\ By JL Thompson, GE Krovitz, and AJ Nelson (2003) New York: Cambridge University Press. 470 pp. $\$ 95.00$ (cloth). ISBN 0-521-82272-6.}

My husband once told me that a good monograph can kill research in a field for a generation. At the time we were talking about Remington Kellogg's ${ }^{1}$ impressive 1936 monograph on the Archaeoceti (archaic Eocene whales). We were puzzling over hand bones from an Egyptian archaeocete that we had excavated and that bore no resemblance to Kellogg's beautiful drawings. When we got down to the fine print, however, we found out that the hands in the drawings were sea-lion hands; no one had the correct hands. Indeed, much more needed to be said about these whales, ${ }^{2}$ but a good monograph, Philip said, gives researchers the idea that what can be done has been done-for a long time.

This pretty well sums up what happened in the paleontology of human growth and development, a field that started with Dart, ${ }^{3}$ and Zuckerman, ${ }^{4}$ and Le Gros Clark ${ }^{5}$ but, ironically, sputtered out after the appearance and publication of Alan Mann's thesis, ${ }^{6,7}$ a comprehensive study of the demography of the South African australopithecine sites. Key to the enterprise was a basis for assigning age at death. Mann used human maturation schedules, arguing that the fossils showed human-like patterns of dental development. Australopithecines, he concluded, matured slowly and were fully deserving of the term "human."

Mann's ${ }^{7}$ monograph was welcomed

() 2004 Wiley-Liss, Inc. DOI 10.1002/evan.20026

Published online in Wiley InterScience (www.interscience.wiley.com). by a field that had little other evidence bearing on the issue. I remember a professor at the University of Texas saying he couldn't imagine how to challenge it. At the University of Michigan, my 1976 paleoanthropology exam included true-or-false questions about australopithecine life span and birth spacing (attributes that would take a field demographer ten years to estimate). Mann's particular conclusion also headed off other research: Whatever had spurred the evolution of the human life cycle was already over in the Pliocene, a point that became a problem for Miocene paleontology. ${ }^{8}$ Although Mann's conclusions prompted an outpouring of thought pieces on human origins ${ }^{9-11}$ the paleontology of human development nearly died out as a field of empiric inquiry, kept alive only by occasional descriptive work. ${ }^{12,13}$

But, as with Kellogg's archaeocete hands, the story was not all told. The fine print should have told us that the comparative data in 1968 were way too thin to decide the question of the antiquity of the human life cycle. It took until 1985 for a real question to arise about Mann's central conclusion. That occurred when Tim Bromage ${ }^{14}$ couldn't make sense of the growth of the face in Taung, the holotype of Australopithecus africanus, unless the child was three years old at death rather than six years old, as traditionally claimed.

Once the question was reopened, research into the antiquity of the human life span and life cycle blossomed: Bromage and Dean ${ }^{15}$ counted perikymata, growth increments visible on tooth surfaces, to estimate the sidereal age at death of key juvenile fossils; Dean ${ }^{16}$ and Smith ${ }^{17}$ reconsidered patterns of dental development; Conroy and Vannier ${ }^{18}$ scanned Taung; and others returned to primates for comparative data on dental development and life history. ${ }^{19,20}$ Taken separately or together, all of these investigators found evidence that australopithecines grew up roughly twice as fast as do living humans, living out their lives on the time scales of apes. Some objected ${ }^{21,22}$ but, in any case, the paleontology of human growth and development had revived as an empiric enterprise. New data and new analyses appeared in a host of studies.

Now that nearly twenty years have passed since Bromage prodded the field back to life, a new book edited by Thompson, Krovitz, and Nelson brings together many recent contributions. This book shows that the paleontology of human growth has reemerged as an empirical field involving the use of large samples and multiple approaches to data. It also shows that the line of argument about the origin of human life history has moved into the genus Homo.

The book is organized into three main sections: contemporary studies on growth or development that bear on paleontological questions; the early record, from australopithecines to Middle Pleistocene Homo; and Upper Pleistocene Homo, particularly Neanderthals. The editors have collaborated in writing summary essays at the end of each section (with rotating first authorship). Although these occasionally are repetitive, some are incisive; all have extensive and useful bibliographies.

The book leads off with an evolutionary perspective on human growth and development by Bogin. He cites the addition of childhood, an interval of dependence beyond weaning, as a key human adaptation. Bogin's point is well taken, but needs qualification: Although humans have undoubtedly elaborated and lengthened childhood to an extreme, ${ }^{23}$ postweaning dependence is not unique to humans. Goodall ${ }^{24}$ describes the first two years after weaning in chimpanzees as childhood because of the close association of weaned juveniles with their mothers. Moreover, mammalian carnivores typically bring down kills for weaned offspring until they manage the skill themselves. ${ }^{25}$ But in all, Bogin provides a useful review that smoothly integrates sex differences in human maturation into an adaptive framework. Also in this section, Liversidge reviews worldwide data on modern human dental development, presenting a paper rich in data for many purposes.

The arguments of the mid-1980s 
were primarily about development and life history, for example, at what age do human ancestors erupt first molars, complete the dentition, or mature. The few articles in the present volume that take up these issues are well worth the effort. Kuykendall provides a comprehensive review of australopithecines, concluding flatly that they achieved dental maturity at ten to twelve years of age, as would a great ape. The lack of objection to this view throughout the book speaks volumes: Clearly, investigators are looking for the evolution of prolonged maturation in the genus Homo.

As reviewed by both Kuykendall and Krovitz, the little known about $H$. habilis dental maturation allies this species with australopithecines. Several papers in this book touch on growth of the almost complete early $H$. erectus juvenile from Nariokotome. The latest on his maturation timing, found elsewhere, ${ }^{26}$ has ramifications for nearly every article. By human standards, the Nariokotome boy is eleven years (tooth formation) or thirteen (bone maturation) years old, although his stature suggests that he is older; by chimpanzee standards, he is seven to eight years old by all criteria (tooth formation, bone maturation, and percent of adult body length achieved). ${ }^{27}$ The first attempt to define his age from incremental lines on tooth surfaces has produced an estimate of a mere eight years at death. ${ }^{26}$ While this certainly is not the last word on Nariokotome, it tentatively places early $H$. erectus development at a surprisingly primitive level.

A study of Atapuerca by Bermúdez de Castro and colleagues stands out as a new test case within a critical period. The Lower Pleistocene site of Gran Dolina contributes three juveniles (one the holotype of $H$. antecessor) for analysis of the pattern of dental development; the Middle Pleistocene site of Sima de los Huesos contributes one (called H. heidelbergensis). When tooth development scores are grouped by a distance analysis, australopithecines and $H$. habilis are allied with great apes, while the Nariokotome boy is uniquely intermediate between great apes and humans. On the other hand, fossils from both Atapuerca sites show greater affinity with $H$. sapiens. In addition, the authors present initial work on perikymata packing on anterior teeth. Fossils from both $H$. antecessor and $H$. heidelbergensis show fewer increments than do $H$. sapiens, suggesting shorter times for crown formation. The results were considerably more surprising, however, when Ramirez Rozzi and Bermúdez de Castro recently looked at Neanderthals. ${ }^{28} \mathrm{Ne}$ anderthal anterior teeth show fewer perikymata than do all other samples, modern or archaic, only two-thirds of the number typical of $H$. sapiens. Because previous studies note nothing peculiar about the relative timing of Neanderthal anterior teeth,17,29 it is likely that this effect is global over the dentition. The most straightforward interpretation is that Neanderthals grew up more quickly than did other Middle and Upper Pleistocene hominids. This, however, leaves Neanderthals with a peculiar relationship between brain size and maturation, two variables that rarely are so out of step. ${ }^{19,30}$ This intriguing research awaits confirmation by an exact count of daily increments in sections from the crown and root of a Neanderthal tooth.

Several studies consider growth in size, using substantial comparative samples. Humphrey describes the attainment of adult femur length from birth to the age of twelve years, using fossils from eleven historic and prehistoric archeological sites. In sample after sample, after the age of two years the femurs of juveniles were smaller than expected compared to those of adults of their own population, judging on the basis of the rate at which contemporary children attain adult size. Humphrey's study may have many applications, from mortality selection to early hominid growth. Kondo and Ishida compare long-bone length and the robusticity of the Dederiyeh Neanderthal infants to more than one hundred historic, prehistoric, and Upper Paleolithic infants. Compared to infants with similar dental maturation (at about two years of age), one of the infants is surprisingly large and robust. Fossils of children large compared to dental age, like Dederiyeh 1 and Nariokotome, become especially distinctive, given Humphrey's findings.

Several studies, each with its own multivariate technique, address ontogeny of the face and skull base. Williams and coworkers consider the classic issue of neotany, evolution of a descendant to resemble the juvenile phase of an antecedent. Neotany is just one of the outcomes of "heterochrony," a series of hypothetical processes that change size or shape. ${ }^{31}$ While Williams and co-authors acknowledge instances of overuse of heterochrony and incorrect use of its arcane terminology, they themselves investigate the subject with surprising clarity, clearly laying out terminology and taking a multivariate approach. They find that neotany does not describe the skulls of modern humans compared to those of Neanderthals or those of the pygmy as compared to the common chimpanzee. McBratneyOwen and Lieberman add to this perspective, finding that human faces retract uniquely during growth, unlike those of chimpanzees.

Antón and Leigh, in a study of cranial dimensions, reconsider the question of an adolescent growth spurt in the Nariokotome boy, noting the difficulty in demonstrating its presence even in recent collections. Ultimately, they conclude that it is safest to stick with the null hypothesis that Nariokotome had an adolescent growth spurt. There is, however, little safe ground left if the boy died at the age of eight years. $^{26}$ If that is correct, Nariokotome simply does not belong on human growth standards.

Two studies consider population variability: Strand Viðarsdóttir and O'Higgens show that face shape is distinctive among human populations from infancy; Krovitz, however, sees an additional degree of difference between Neanderthals and modern humans. She finds that growth patterns distinguish Neanderthals from human populations at the earliest represented ages. Joining a growing number of scientists who consider developmental criteria for membership in the genus Homo ${ }^{32}$ and the species sapiens, ${ }^{28}$ she supports placing Neanderthals into $H$. neanderthalensis.

In sum, the terrain couldn't be more 
different from that envisioned by my 1976 exam. New evidence suggests we would be hard pressed to call the maturation of Homo erectus modern, much less that of Australopithecus. It now seems likely that our distinctive life history-our large and helpless infants and difficult birth, early weaning, extended childhood, slow growth, sex differences in growth stages, and long life span-evolved substantially during the Pleistocene. Yet we have only begun to document the evolution of the life history of Homo: We are in the midst of debates on the primitiveness of $H$. erectus and need to resolve increasing contradictions in Neanderthal life history. We await a brave curator somewhere who will allow a single Neanderthal tooth to be sectioned; much depends on it. As this volume shows, there are many approaches to the paleontology of growth and development. Moreover, the time is past when a monograph could sum up all we know.

\section{REFERENCES}

1 Kellogg R. 1936. A review of the Archaeoceti. Washington, D.C.: Carnegie Institute of Washington.

2 Gingerich PD, Smith BH, Simons EL. 1990. Hind limbs of Eocene Basilosaurus isis: evidence of feet in whales. Science 249:154-157.

3 Dart RA. 1925. Australopithecus africanus: the man-ape of South Africa. Nature 115:195-199.

4 Zuckerman S. 1928. Age-changes in the chimpanzee, with special reference to growth of the brain, eruption of teeth, and estimation of age; with a note on the Taungs ape. Proc Zool Soc London 1928:1-42.

5 Le Gros Clark WE. 1947. Observations on the anatomy of the fossil Australopithecinae. J Anat 83:300-333.

6 Mann AE. 1968. The paleodemography of Australopithecus. Ph.D. thesis, University of California, Berkeley.

7 Mann AE. 1975. Some paleodemographic aspects of the South African australopithecines. Philadelphia: University of Pennsylvania.

8 Simons EL, Pilbeam DR. 1971. A gorilla-sized ape from the Miocene of India. Science 173:2327.

9 Tanner NM, Zihlman A. 1976. Women in evolution: part I, innovation and selection in human origins. Signs 1:585-608.

10 Lancaster JB. 1978. Carrying and sharing in human evolution. Hum Nat 1:82-89.

11 Lovejoy CO. 1981. The origin of man. Science 211:341-350.

12 Vlček E. 1973. Postcranial skeleton of a Neandertal child from Kiik-Koba, U.S.S.R. J Hum Evol 2:537-544.

13 Skinner MF, Sperber GH. 1982. Atlas of radiographs of early man. New York: Alan R. Liss.

14 Bromage TG. 1985. Taung facial remodeling: a growth and development study. In: Phillip V. Tobias, editor. Hominid evolution: past, present and future. New York: Alan R. Liss. p 239-245.

15 Bromage TG, Dean MC. 1985. Re-evaluation of the age at death of immature fossil hominids. Nature 317:525-527.

16 Dean MC. 1985. The eruption pattern of the permanent incisors and first permanent molars in Australopithecus (Paranthropus) robustus. Am J Phys Anthropol 67:251-257.

17 Smith BH. 1986. Dental development in Australopithecus and early Homo. Nature, London $323: 327-330$

18 Conroy GC, Vannier MW. 1987. Dental development of the Taung skull from computerized tomography. Nature 329:625-627.

19 Smith BH. 1989. Dental development as a measure of life history in primates. Evolution 43:683-688.

20 Kuykendall K, Mahoney CJ, Conroy GC. 1992. Probit and survival analysis of tooth emergence ages in a mixed-longitudinal sample of chimpanzees. Am J Phys Anthropol 89:379-399.

21 Mann AE, Lampl M, Monge J. 1987. Maturational patterns in early hominids. Nature 328 : 673-675.

22 Simpson SW, Lovejoy CO, Meindl RS. 1990. Hominoid dental maturation. J Hum Evol 19:285297.

23 Kaplan H. 1997. The evolution of the human life course. In: Wacter K, Finch CE, editors. Between Zeus and salmon: the biodemography of aging. Washington, D.C.: National Academy of Sciences. p 175-211.

24 Goodall J. 1986. The chimpanzees of Gombe: patterns of behavior. Cambridge: Belknap.

25 Ewer RF. 1973. The carnivores. Ithaca: Cornell University Press.

26 Dean MC, Leakey MG, Reid D, Schrenk F, Schwartz GT, Stringer C, Walker A. 2001. Growth processes in teeth distinguish modern humans from Homo erectus and earlier hominins. Nature 414:628-631.

27 Smith BH. 1993. The physiological age of KNM-WT 15000. In: Alan Walker, Richard Leakey, editors. The Nariokotome Homo erectus skeleton. Cambridge: Harvard University Press. p 196-220.

28 Ramirez Rozzi FV, Bermúdez de Castro JM. 2004. Surprisingly rapid growth in Neanderthals. Nature 428:936-939.

29 Tompkins RL. 1996. Relative dental development of upper Pleistocene hominids compared to human population variability. Am J Phys Anthropol 99:103-118.

30 Smith RJ, Gannon PJ, Smith BH. 1995. Ontogeny of australopithecines and early Homo: evidence from cranial capacity and dental eruption. J Hum Evol 29:155-168.

31 Gould SJ. 1977. Ontogeny and phylogeny. Cambridge: Belknap.

32 Wood B, Collard M. 1999. The human genus. Science 284:65-71.

B. Holly Smith
Museum of Anthropology
1109 Geddes
University of Michigan
Ann Arbor, Ml 48109
E-mail: bhsmith@umich.edu

